\title{
Student Exchange: The First Step Toward International Collaboration
}

\author{
Abdullah Atalar
}

\section{Introduction}

In light of globalization in the twenty-first century, businesses are seeking employees with skills that would make them more competitive in the international arena. Hence, the graduates of universities need to have the ability to interact with people from other cultures and different backgrounds [1] to be successful in the international labor market. They are required to work in multicultural teams and speak other languages. This creates new challenges for institutions of higher education [2]. Universities must prepare their students for such a globalized environment, thus enabling their graduates to be more employable. There is a growing pressure on the faculty and administration of universities to internationalize their campuses, curricula and classrooms. They need to prepare their students for global work and global citizenship. ${ }^{1}$ Their institutions, programs and courses should be positioned to help globalize the higher education environment and to prepare students for global markets. The Organization of Economic Cooperation and Development (OECD) defines an internationalized curriculum as one which has an "international orientation in context, aimed at preparing students for performing in an international and multicultural context, and designed for domestic students as well as foreign students [4]."

One of the most effective methods of developing an international experience is for students to join a student exchange or study abroad program for a semester or two. Such programs help students be multilingual individuals with intercultural competencies and develop lasting friendships in other countries contributing to world peace [5].

\footnotetext{
${ }^{1}$ Global citizens are people with skills in intercultural communication and with awareness and respect for cultural differences and the complex and interdependent nature of the world [3].
}

A. Atalar $(\bowtie)$

Bilkent University, Ankara, Turkey

e-mail: aatalar@bilkent.edu.tr
Because of these benefits, universities are trying to expand their student exchange programs and encourage their students to participate in such programs. For example, the European Union is providing financial support to European Universities in 37 countries for student mobility through the Erasmus program [6], enabling student exchange in over 900 partner universities. Moreover, many universities offer second or third language courses to make their graduates multilingual. In some universities, such courses are even a graduation requirement. The recruitment of more international and ethnically diverse students is a priority for universities with a serious internationalization goal. The integration of international students with domestic students helps increase the intercultural experience of all students.

\section{Description of Exchange Programs}

\subsection{Undergraduate Student Exchange Programs}

An exchange program allows students from two universities in two different countries to spend a semester or two in the other institution while taking courses. Students from the "home university" become visiting students in the "host university" for a limited time to increase their international exposure. This arrangement is made possible by a student exchange agreement between the two universities. Typically, home universities have a minimum grade point average (GPA) requirement for undergraduate students to be eligible for an exchange program. The students also need to satisfy the minimum requirements of the host university. These requirements can include a minimum GPA or a specified level of proficiency in the host country's language. The number of students in the exchange program hosted by the two universities should be about equal in both directions for a sustainable agreement. If an approximate balance is not satisfied over a period of time, the agreement may come to an end. 
Students pay the tuition of their own universities only if such tuition exists. They take courses at the host institution to be counted toward the degree requirements in their home institution. Students bear the costs of travel, accommodation, food and books while they are at the host institution.

\subsection{Graduate Student Exchange Programs}

To increase research collaboration between two universities, a graduate student exchange program is a useful tool. In such a program, for example, graduate students may spend a period in the host university possibly using the facilities or equipment of the host university not available at the home institution. In the same period, it is also possible for graduate students to take courses in the host university not given in the home university. In a typical arrangement, the host institution provides a tuition waiver and stipends and/or free accommodation to visiting graduate students.

In many developed countries, the number of students studying (STEM) science, technology, engineering and mathematics subjects is decreasing, and it is becoming more and more difficult to find native graduate students [7] despite the efforts to increase their interest [8]. This is not the case in many developing countries. Hence, the STEM workforce in developed nations depends to a large extent on foreign-born mathematicians, scientists and engineers. A graduate student exchange agreement between a developed country and a developing country and the resulting research collaboration are beneficial to both sides: the developing country supplies highly motivated graduate students while the developed country has a rich research infrastructure and distinguished faculty members. Home universities profit from this arrangement in the form of collaborative research papers and the expertise obtained by the graduate students. Research universities in developed nations prefer to use graduate student exchange agreements as a tool to attract and select graduate students for their Ph.D. or post-doctoral programs.

\section{Principles for Operating Exchange Programs}

\subsection{Exchange Program Coordinators}

Every department that is involved in an undergraduate student exchange program should appoint a faculty member or a staff member from the department as the exchange coordinator. The duties of an exchange program coordinator can be listed as follows:
- Inform the students in the department about the exchange system and about the partner institutions.

- Keep in constant contact with the exchange program coordinators of the partner universities.

- Inspect the regulations, academic rules and courses of the corresponding departments in partner universities for the purpose of informing the potential exchange students of the department.

- Advise students about the courses they may take while they are in partner universities. Before the students depart for the host country, it is important for students to know how they will satisfy the home institution's requirements with the courses they take at the host university. It is obviously undesirable if the courses taken abroad are not counted toward the degree requirements of the home institution.

- Be a contact point for the outgoing students and be available when they need academic advice.

- Report to the department the grades of the courses taken abroad by the outgoing exchange students upon their return, possibly after converting them using an equivalency table.

\subsection{Transfer of Undergraduate and Graduate Credits}

There may be differences in the grading policies of different institutions. For this reason, some universities only transfer the number of successfully completed courses in the host institution toward the home institution graduation requirements: the students are exempted from an equal number of courses in their home institution's curricula. However, the grades of the courses taken during the exchange period will not be included in the student's grade point average calculation of the home institution. On the other hand, some institutions may prefer to transfer the courses as well as their grades, using a grade equivalency table. In any case, the students should be aware of the consequences of the exchange system and the grades they get abroad before they go for an exchange.

\subsection{Thesis Advisors from Both Institutions}

In the case of a graduate student exchange program, two faculty members in the partner universities are appointed as thesis advisors for each exchange student. The research subject that the graduate student undertakes should be within 
the interest and expertise of both faculty members. Any scientific publication that results from this collaboration is typically authored by the graduate student and the thesis advisors from the two institutions.

\section{Advantages and Disadvantages of Exchange Programs}

\subsection{From the Students' Perspective}

Students participating in student exchange programs often enjoy and benefit from the program. Many students feel that the insights developed during the program enable them to feel a deeper interest in the country of exchange, making them more tolerant and adaptable to cultural differences. On the academic side, students can choose from a diversity of courses at the host institution, increasing their preparation for the job market or graduate school.

Attending a student exchange program in a good caliber research university is a tremendous advantage for students having a goal of attending a post-graduate program. The grades they get and their behavior during the exchange period in the host institution give the host institution reliable data points if the same student applies for graduate programs at the host institution after graduation.

On the other hand, financial considerations, administration and cultural difficulties are the highest perceived drawbacks of an exchange program [9]. A majority of students do not apply to an exchange program if there is no financial support. The European Union's Erasmus program tries to alleviate this problem by providing significant financial support for students participating in an exchange program among the universities of the member countries.

Administrative difficulties such as visa requirements, university bureaucracy or difficulty with the equivalency of courses taken may also deter students from joining an exchange program. Countries having difficulty attracting exchange students should spend a significant effort to reduce such problems. The perceived difficulty of the university bureaucracy may be reduced as a result of this effort, helping the domestic students as well. Countries having difficulty attracting exchange students should also consider easing visa and residence permit requirements for exchange students.

Moving to a new country and entering a new culture can be very challenging. Many students may be confused or stymied by the differences they encounter especially during the first month of their visit [10]. Many students end up experiencing some degree of "culture shock." For example, food served may be the most difficult aspect of their experience, contributing to culture shock. This shock could be in the form of feelings of frustration, anxiety or anger, a lack of motivation or a constant sense of being ill. These are all normal reactions when adjusting to a new lifestyle. The adaptation period may not be so easy. Many students feel that going through this difficult time makes them stronger persons in the end. They certainly will have interesting stories to share with family and friends upon their return home.

Evidence shows that many of the exchange programs are within the countries of the developed world. Students prefer to remain in their comfort zone, staying away from universities in the developing world, avoiding more challenging and possibly more rewarding experiences. Analyses also show that students who participated in student exchange programs start jobs with higher salaries and have a higher probability of opting for graduate programs [11].

\subsection{From the University's Perspective}

There is a tendency in many western universities to increase their tuition income through full-time international students [12]. Giving full or partial scholarships to international students and increasing the number of exchange students help increase the number of fee-paying international students. Many universities in the UK, USA and Australia are particularly successful in recruiting international students, capitalizing on the fact that English is the language of the country as well as the medium of instruction in the university. Because of international student fees covering the full cost of the students, revenues from the export of education services have become an important part of the budgets of such universities. Many universities have lifted the quotas that previously limited the number of foreign students.

On the other hand, a significant number of other countries encourage their universities to increase their foreign student counts and exchange student counts, not for the purpose of increasing university revenues, but to cultivate soft power and subsequently increase international trade between the countries. Obviously, this aim can be fulfilled only if international students have a positive experience in the country they visit. In such a case, full-time international or exchange students become natural ambassadors, whether they stay in that country or return to their home countries. They engage in trade and contribute to the relations between the countries in a positive way [13]. This engagement has become so common that in the world university rankings $[14,15]$, the percentage of international students has become one of the factors contributing to rankings. This factor contributes 2.5$5 \%$ toward the overall ranking. It is believed that student mobility is a soft power strategy increasing international trade and the influence of countries on each other. In addition, the experiences of students participating in exchange 
programs in a university in the developed world may, in the long run, impact political institutions and influence political behavior in their home countries in a positive direction [16].

Many developed nations have difficulty finding good quality students for their Ph.D. programs. Having attractive undergraduate student exchange programs is a powerful tool to attract good quality students to the Ph.D. programs of the host institutions. If the home institution is in a developing nation, outgoing exchange students usually have a better academic standing than the average. It is observed that those students prefer to apply to graduate programs of universities where they spent a semester or two as an exchange student.

Developing nations also try to attract foreign students to their universities to gain prestige and to improve the cultural composition and diversity of the student body. To make their exchange programs attractive for students from developed nations, some universities provide free accommodation for exchange students.

Since English is the dominant language of the world, having English as the medium of instruction makes a host institution very attractive [17]. Students with higher GPA's end up in such institutions as exchange students. If their experience is positive, they prefer to apply for graduate programs in those universities. For example, most of the universities in the Netherlands have English as the medium of instruction, and as a consequence they are very successful in attracting good international undergraduate and graduate students. Although France is the number one tourist destination of the world, the number of international students in French universities lags behind the USA, Britain and Australia. The French government is simplifying student visa regulations and is encouraging its universities to teach more courses in English to lure foreign students [18], and the number of such courses has increased fivefold in the last four years.

\section{Maintaining Exchange Programs}

\subsection{Things to Do}

1. Universities should setup an "international office" that takes care of full-time international students and exchange students. This office should have the responsibility to recruit such students. It should also provide help and information to incoming exchange students while they are getting their visas or residence permits. If needed, the embassy of the host country in the home country of the student should be contacted to ease the bureaucratic processes. In short, everything related to international and exchange students should be done under the umbrella of this office.

2. A host family system should be setup for the accommodation of exchange students during their visit. With such a system, exchange students are more immersed in the culture of the country as compared to a system where the students live in a dormitory. Being a host family is often a voluntary service and there might be no monetary compensation, although some countries may allow a tax deduction for such a voluntary service.

3. The international office should organize orientation programs for the exchange students during their first week. During this program, the office should give printed documents, pamphlets or links to web pages which provide useful information to the exchange students in their initial difficult weeks. The information package should include things like the history of the university and information about campus life, entertainment venues, concert halls, museums, local currency, banking, food, cafes, pubs, restaurants, sports facilities, course registration methods, the grading and credit system, the library, computer facilities, traffic rules, shopping, places of worship, bookstores, safety matters, health care, the smoking policy, medical insurance, housing, transportation, parking, useful websites and travel information.

4. The international office should also organize a welcome picnic in the first week. This can provide a good start for exchange students and give them a chance to meet each other and local students.

5. The international office should create a wellmaintained website devoted to exchange students. An e-mail group, a Facebook account or a Twitter account may also serve as a way to distribute information.

6. The international office should organize cultural trips to nearby destinations. For example, archeological sites, museums or touristic/historic nearby cities or locations may be good choices.

7. The international office should inform the students about the academic rules and regulations. While plagiarism and cheating may be common in some countries [19], such actions may be harshly punishable in some other countries.

8. The international office should inform the students about the laws of the country. For example, some countries have strict laws about alcohol or drug use, while in some others the rules on the use of such drugs or substances may be very liberal.

9. The university should provide local language courses designed for international students. Such courses must be designed to be useful in day-to-day life with an emphasis on vocabulary and pronunciation components 
rather than a fully academic language course with grammar, reading and writing components.

10. The international office should provide psychological counseling for those students who are in culture shock or in some kind of difficulty.

11. The international office should organize regular social events bringing domestic and international students together. Students who participated in international exchange programs previously may be invited to such events since they are usually more willing to participate in such occasions. It is also very desirable to organize a social good-bye event at the end of the semester for the exchange students leaving for their home countries.

\subsection{Things not to Do}

The host university should not ignore the special needs of international students. The absence of an international office or an international office not doing its job properly may cause a decrease in the number of incoming exchange students. It should not be overlooked that word of mouth of visiting students is an important aspect of the university's prestige building.

\section{Termination of Exchange Programs}

\subsection{Things that Can Go Wrong}

If the balance of incoming and outgoing students is not even, there may be problems in the long run. Many exchange agreements include a clause that enables termination of the agreement if a balance of the number of incoming and outgoing students is not satisfied within a specified time period. Negative political developments and relations between the countries or safety concerns arising from terrorism in countries may also force the home universities to cancel or discourage exchange programs to those countries, reducing the number of incoming exchange students in victim countries.

\section{Good Examples of Exchange Programs}

\subsection{European Union Erasmus Program}

The Erasmus [6] exchange program of the European Union was started in the late 1980s. The purpose of the program is to increase cooperation between the partner countries by aiding the growth of international study and giving students an excellent chance to experience another country [20]. Students typically go to another country for three to twelve months. Between 2014 and 2017, each year about 300,000 university students joined this program to study in a partner institution of another country. France and Germany send the highest number of students (about 40,000 each year) to other countries (see Fig. 1), while Spain is the most popular hosting country (about 42,000 students each year) (see Fig. 2).

In Fig. 3, the ratios of outgoing to incoming student counts are given for different European countries for the academic year 2014/2015. English-speaking or warmer climate countries seem to be popular as exchange destinations, while the students in English-speaking countries are not so willing to leave their universities for experience in another country.
Fig. 1 Number of outgoing Erasmus exchange students from leading countries in 2015 [21]

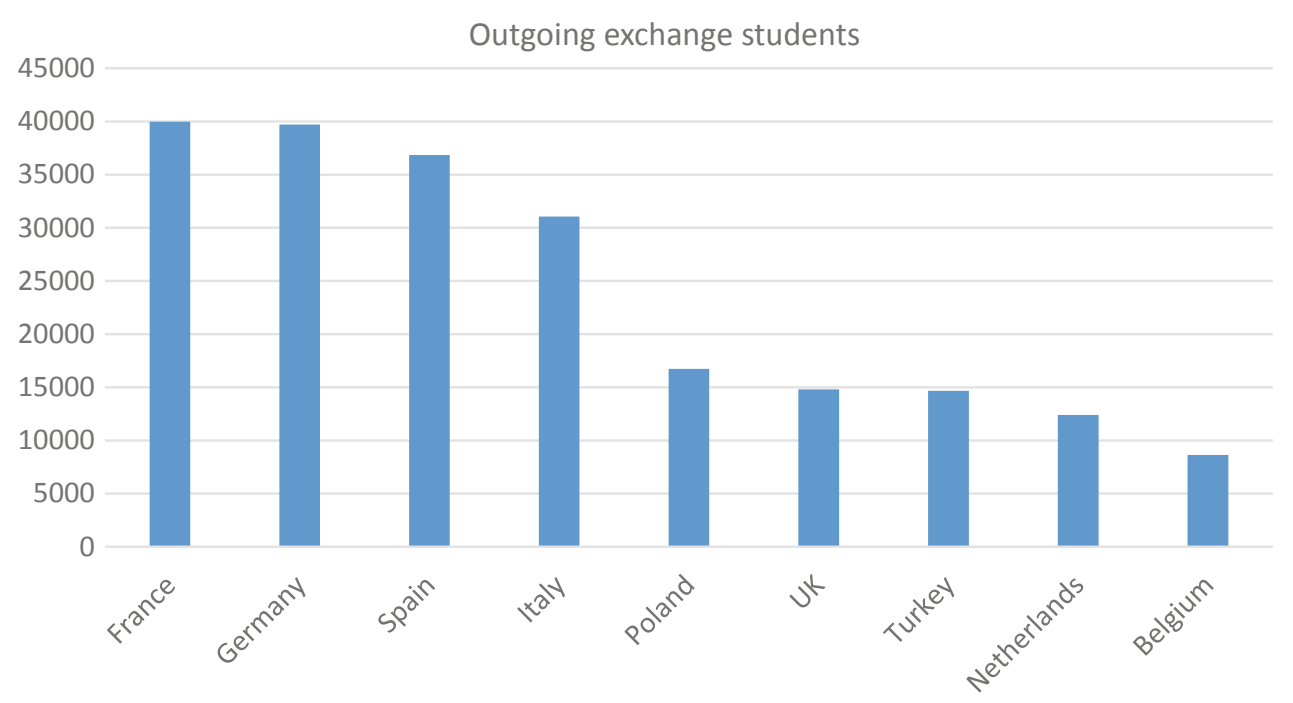


Fig. 2 Number of incoming Erasmus exchange students from leading countries in 2015 [21]
Fig. 3 Outgoing to incoming exchange student ratio for the ERASMUS program of different countries (2015) [21]
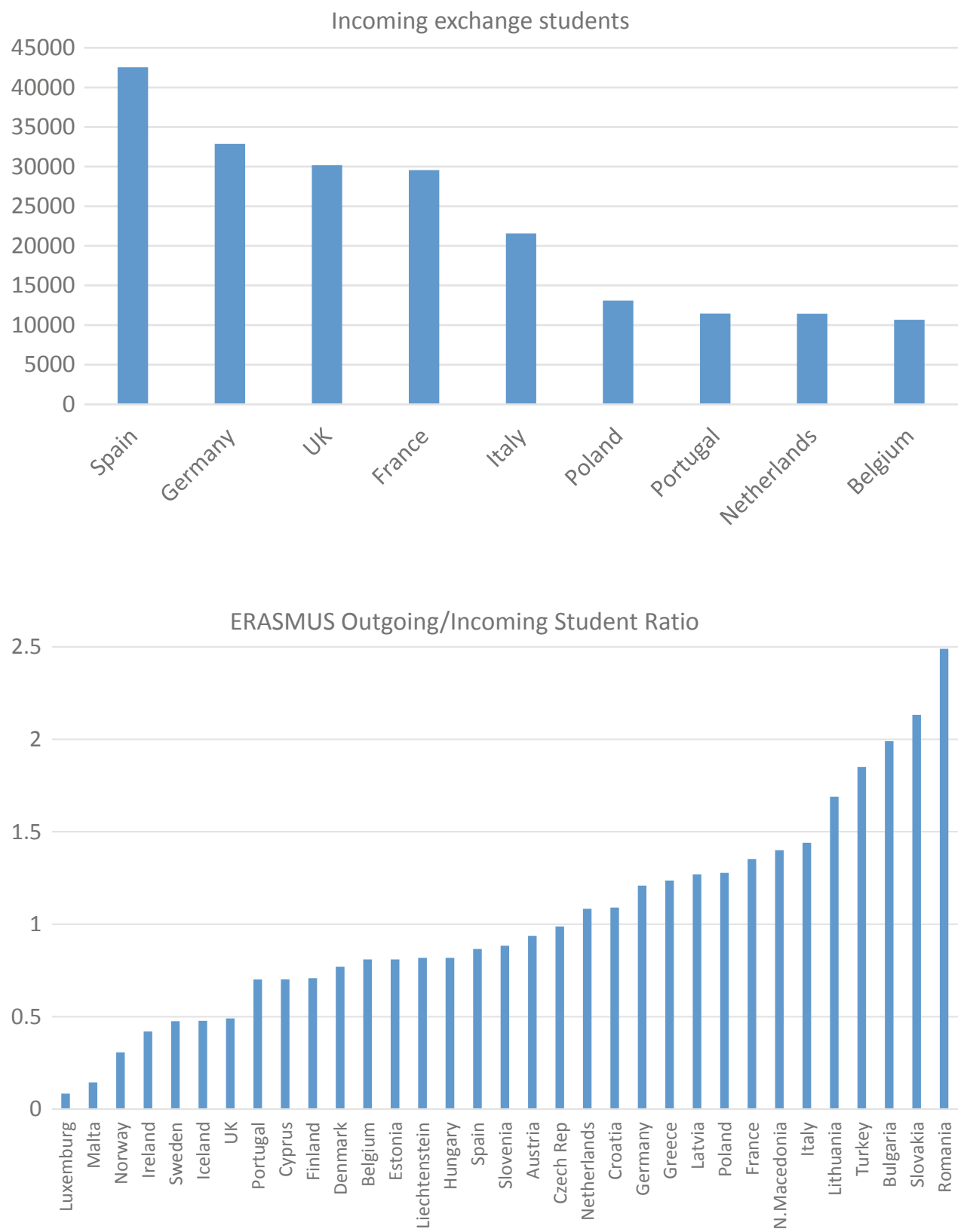

In the Erasmus program, students are eligible to receive grants for studying or for being trained abroad for a maximum of 12 months per each of the three cycles of study:

1. Bachelor degree programs

2. Master or equivalent degree programs

3. Doctoral degree programs.

Students registered in a higher education institution in the partner countries and enrolled in a study program leading to a recognized degree or a tertiary level qualification (up to the level of Doctorate) are eligible. The exchange program is carried out through inter-institutional agreements between the receiving and sending institutions. All such institutions must be awarded the Erasmus Charter for Higher Education. In 2015, the European Union contributed about 1500 Euros for each student participating in the exchange program to help cover the extra costs [21].

\subsection{Other Examples}

AFS-USA is a non-profit organization providing international learning experiences and study abroad programs in 80 countries for the purpose of fostering peace in the world [22]. Most exchange students are high-school graduates, 
spending one year or one semester in a host institution in another country. A network of volunteer host families worldwide provides accommodation for exchange students lowering the cost and increasing the cultural immersion.

\section{International Collaborative Courses, Another Avenue for Student Exchange}

Through the advances in communication and Internet technologies, a new type of learning environment is emerging [23]. Digital network technologies have a great potential for Internet-based collaboration, shared knowledge making and joint action across the boundaries of nations [24]. Instead of limiting teaching to local traditional classrooms, this new type of online classroom provides a multilingual and highly diverse learning environment. In such cross-border classrooms, students are required to collaborate with students from overseas for the purpose of solving a problem within the framework of courses they take in their own universities. They face multiple perspectives and multiple approaches in the solution of the problem, making the learning experience more valuable [25]. In a typical setting, the instructors on each side should have prior online meetings to organize the course, possibly by using video conferencing methods. Students are formed into four- to six-member teams with an equal number of students from both sides. A web-based course management system like Moodle [26] detailing goals, lesson plans and assignments is a very useful component of the course. Discussion forums in such course management systems provide a fruitful environment for discussion. Such discussion forums are especially convenient if the collaborating universities lie in quite different time zones.

If the time zones are not so different, possible collaboration technologies among the students of two universities include instant messaging applications like WhatsApp [27] and face-to-face communication and video conferencing applications like Skype [28] or Facetime. Obviously, popular social media tools [29] like Facebook [30] or Twitter [31] can also be used for such courses, making collaboration among students even more interesting. Project reports and presentations can be prepared using cloud-based tools like Google Docs [32] where the students can create and edit the reports or presentations online in a collaborative manner. Such courses not only bring the students of two universities together, but also the instructors from both sides and increase the collaboration and understanding between them. Such relations and partnerships may eventually lead to dual degree programs involving the two universities.

\section{Other Forms of Collaboration}

\subsection{Faculty Exchange Programs}

Many research universities have sabbatical programs. Sabbaticals are paid leaves for a period of six months to 12 months for the purpose of professional development [33]. Typically, faculty members are eligible for sabbatical leaves after six or seven years of service. This paid leave period should not be interpreted as an increased vacation period; rather it is an investment of the university to increase the efficiency of the research and teaching force [34]. It also serves the faculty member on sabbatical as relief from routine work duties, providing an opportunity for renewal.

Faculty members who are eligible for a sabbatical program may want to apply to higher caliber universities for a prospect to spend a year. Those host institutions may prefer to accept such applications if the faculty member on sabbatical can teach one course or if the faculty member can contribute to research, without a long-term commitment to that faculty member. Sending institution benefits from the teaching experience gained by the faculty member or from the research collaboration which may have resulted.

In addition, two universities of nearly equal standing may want to sign faculty exchange agreements. Some universities have faculty exchange programs which provide benefits for faculties as well as their universities. An opportunity to lecture in another university is an invaluable experience [35]. Experience abroad helps faculty members enhance their understanding of global issues. Research collaborations can start during the time the faculty member interacts with the host institution's faculty. Upon return to their home institutions, those faculties increase global content in their courses, bringing a clear benefit to their home institutions. Many research collaborations started during a faculty visit continue for many years if both sides find it fruitful. Such collaborations bring the two partner universities even closer [36].

The Erasmus program of the European Union also supports higher education staff mobility between European countries. In 2017, about 62,000 faculty members benefited from this program. Poland sent the highest number to other countries while Spain received the highest number of visitors. Figure 4 depicts the number of faculty exchanged between different countries for the year 2017. In the same year, the Erasmus program of the European Union contributed on average 1872 Euros per staff member to support the short-term mobility. 
Fig. 4 Faculty exchange counts for European countries supported by the Erasmus program (2017) [21]

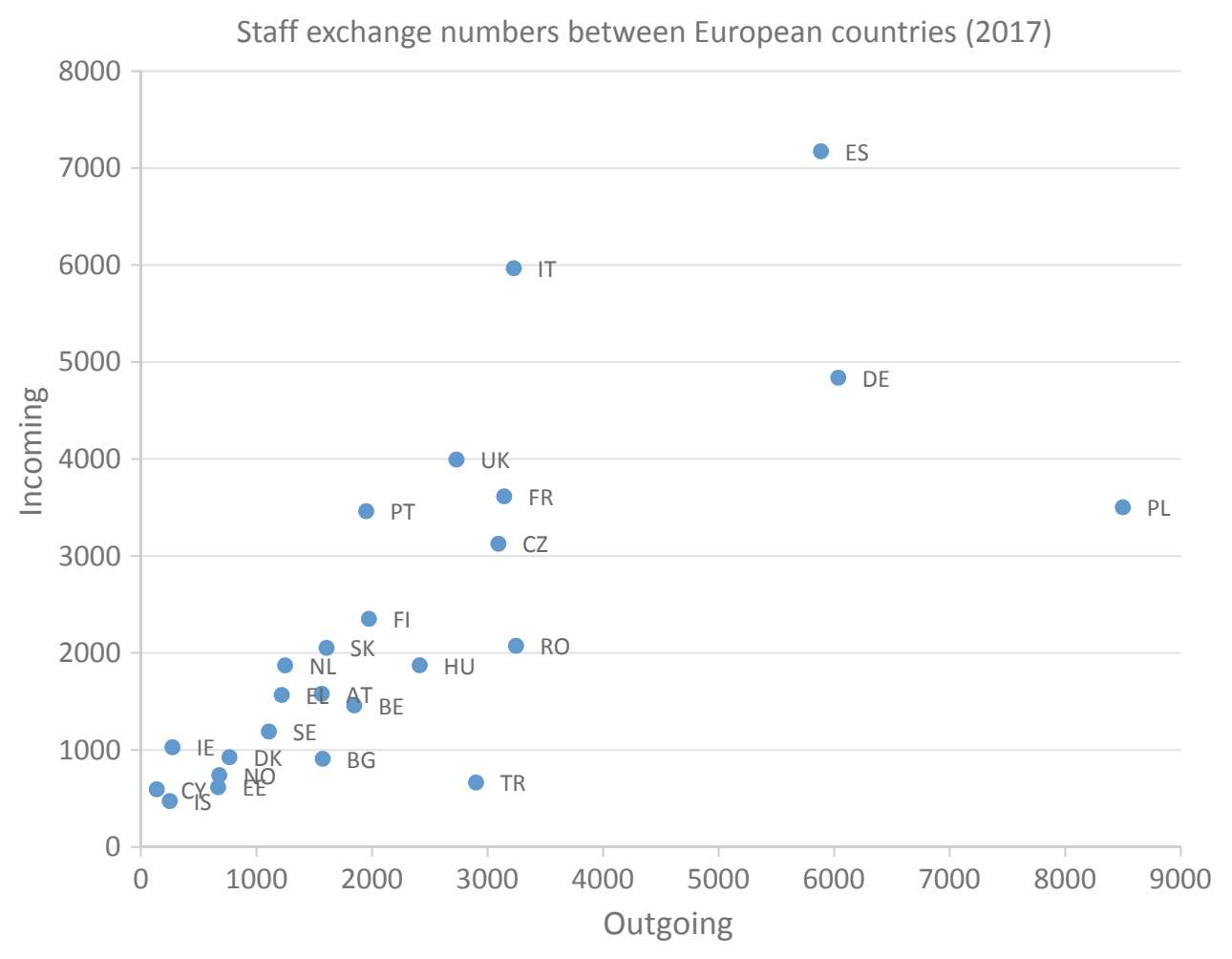

\subsection{International Joint or Dual Degree Programs}

In a typical undergraduate joint or dual degree program, the students spend two years in one institution and two years in another institution. With successful completion of four years in a dual degree program, the students get two separate diplomas from each institution. In the case of a joint degree program, the students receive a single diploma containing the seals and signatures of both universities. In both cases, the students pay the corresponding tuition of the institutions only for the time spent in that institution.

Joint or dual degree master's programs are more widespread. It is believed that joint or dual degree programs better prepare students in terms of academic and intellectual capabilities. Obviously, gaining qualifications from more than one country increases the chance of employment. Graduates of such programs can be more suited to be leaders in international ventures [37]. Typically, students with higher ambitions choose such programs.

\subsection{Research Workshops Between Two Institutions}

The faculty members from two universities can arrange a research workshop lasting one or two days. This can be considered a mini conference where the faculty members from both sides present their latest findings in their research area. Informal dinners and social events can help faculty members from each side to come closer together. In a typical arrangement, the host institution covers all costs related to accommodation, food and transportation from and to the airport, while the visiting faculty members pay their own airfare. Many European Union research programs sponsor such events to increase collaboration between the member countries. In successful collaborations, regular research workshops are held every year with alternating hosts.

\section{Conclusion}

Universities in both developing and developed nations use student exchange as the first mechanism to increase collaboration between universities. It is also used to attract full-time international undergraduate students for increased tuition income and to lure graduate students for a stronger research program. The presence of international exchange students in a university improves the diversity in the classroom and the interaction of students with different cultures, developing the intercultural competencies of the students and helping them become global citizens. In the long run, such a program aids trade between the countries and contributes to good relations, to understanding between nations and eventually to world peace. 


\section{References}

1. Fantini, A. E., Arias-Galicia, F., \& Guay, D. (2001). Globalization and 21st century competencies: Challenges for North American higher education. http://conahec.org. Accessed September, 2018.

2. Rizvi, F. (2006). Internationalization of curriculum: A critical perspective. In The SAGE handbook of research in international education (pp. 337-350). Thousand Oaks: SAGE.

3. Stevens, C. R., \& Campbell, P. J. (2006). Collaborating to connect global citizenship, information literacy, and lifelong learning in the global studies classroom. Reference Services Review, 34(4), 536556.

4. Organisation for Economic Co-operation and Development. (1996). Internationalizing the curriculum in higher education. Paris: OECD.

5. Clinton, W. J. (2000). Proclamation international education week. Washington, DC: The White House.

6. European Union. Erasmus programme. http://www. erasmusprogramme.com. Accessed September, 2018.

7. Hossain, M., \& Robinson, M. G. (2012). How to motivate US students to pursue STEM (science, technology, engineering and mathematics) careers. US-China Education Review A, 4, 442-451.

8. VanMeter-Adams, A., Frankenfeld, C. L., Bases, J., Espina, V., \& Liotta, L. (2014). Students who demonstrate strong talent and interest in STEM are initially attracted to STEM through extracurricular experiences. CBE-Life Sciences Education, 13, 687-697.

9. Bakalis, S., \& Joiner, T. A. (2004). Participation in tertiary study abroad programs: The role of personality. International Journal of Education Management, 18(5), 286-291.

10. Zhou, Y., Jindal-Snape, D., Topping, K., \& Todman, J. (2008). Theoretical models of culture shock and adaptation in international students in higher education. Studies in Higher Education, 33(1), $63-75$.

11. Messer, D., \& Wolter, S. C. (2007). Are student exchange programs worth it? Higher Education, 54(5), 647-663.

12. Altbach, P. G., \& Knight, J. (2007). The internationalization of higher education: Motivations and realities. Journal of Studies in International Education, 11(3/4), 290-305.

13. Haugen, H. O. (2011). China's recruitment of African university students: Policy efficacy and unintended outcomes. Globalisation, Societies and Education, 11(3), 315-334.

14. Times Higher Education. World university rankings: Times higher education (THE). https://www.timeshighereducation.com/worlduniversity-rankings. Accessed November, 2018.

15. QS world university rankings-Methodology: Top universities https://www.topuniversities.com/qs-world-university-rankings/ methodology. Accessed November, 2018.

16. Atkinson, C. (2010). Does soft power matter? A comparative analysis of student exchange programs 1980-2006. Foreign Policy Analysis, 6(1), 1-22.
17. Doiz, A., Lasagabaster, D., \& Sierra, J. M. (2013). English-medium instruction at universities: Global challenges. Bristol: Multilingual Matters.

18. Campus France: Studying in France. https://www.campusfrance. org/en. Accessed November, 2018.

19. Jones, D. L. (2011). Academic dishonesty: Are more students cheating? Business Communication Quarterly, 74(2), 141-150.

20. Gonzales, C. R., Mesanza, R. B., \& Mariel, P. (2010). The determinants of international student mobility flows: An empirical study on the Erasmus programme. Higher Education, 62(4), 413430.

21. European Union. (2015). Annex I Erasmus+ programme annual report (Statistical annex). http://ec.europa.eu/programmes/ erasmus-plus/about/statistics_en. Accessed February 3, 2019.

22. AFS intercultural programs USA. https://www.afsusa.org/. Accessed November, 2018.

23. Starke-Meyerring, D., \& Wilson, M. (2008). Designing globally networked learning environments. Rotterdam: Sense Publishers.

24. Kalantzis, M., \& Cope, B. (2012). New learning: Elements of science education. Champaign, IL: The Learner.

25. Starke-Meyerring, D., \& Andrews, D. (2006). Building a shared virtual learning culture: An international classroom partnership. Business Communication Quarterly, 69(1), 25-49.

26. Moodle-open source learning platform. https://moodle.org. Accessed November, 2018.

27. WhatsApp. www.whatsApp.com. Accessed November, 2018.

28. Skype: Communication tool for free calls and chat. https://www. skype.com. Accessed November, 2018.

29. Mazer, J. P., Murphy, R. E., \& Simonds, C. J. (2006). I'll see you on "Facebook": The effects of computer-mediated teacher self-disclosure on student motivation, affective learning, and classroom climate. Communication Education, 56(1), 1-17.

30. Facebook. https://www.facebook.com. Accessed November, 2018.

31. Twitter. It's what's happening. https://twitter.com. Accessed November, 2018.

32. Google docs - Create and edit documents online, for free. https:// www.google.com/docs/about. Accessed November, 2018.

33. Davidson, O. B., Eden, D., Westman, M., Cohen-Charash, Y., Hammer, L. B., Kluger, A. N., et al. (2010). Sabbatical leave: Who gains and how much? Journal of Applied Psychology, 95(5), 953964.

34. Kimball, B. (1978). The origin of the Sabbath and its legacy to the modern sabbatical. Journal of Higher Education, 49(4), 303-315.

35. Miglietti, C. (2015). Teaching business classes abroad: How international experience benefits faculty, students and institutions. Journal of Teaching in International Business, 26(1), 46-55.

36. Sisco, L. A., \& Reinhard, K. (2007). Learning to see what's invisible: The value of international faculty exchange. Business and Professional Communication Quarterly, 70(3), 356-363.

37. Asgary, N., \& Robbert, M. A. (2010). A cost-benefit analysis of an international dual degree programme. Journal of Higher Education Policy and Management, 32(3), 317-325.
Open Access This chapter is licensed under the terms of the Creative Commons Attribution 4.0 International License (http:// creativecommons.org/licenses/by/4.0/), which permits use, sharing, adaptation, distribution and reproduction in any medium or format, as long as you give appropriate credit to the original author(s) and the source, provide a link to the Creative Commons license and indicate if changes were made.
The images or other third party material in this chapter are included in the chapter's Creative Commons license, unless indicated otherwise in a credit line to the material. If material is not included in the chapter's Creative Commons license and your intended use is not permitted by statutory regulation or exceeds the permitted use, you will need to obtain permission directly from the copyright holder. 